\title{
Innovative Sustainable Water Management Practices in Solar Residential Design
}

\author{
C. Jason Mabry ${ }^{1}$, Franca Trubiano ${ }^{1}$ \\ ${ }^{1}$ Georgia Institute of Technology, Atlanta, Georgia
}

\begin{abstract}
This paper communicates the results of an architectural research project which sought innovative design strategies for achieving energy and resource efficiencies in water management systems traditionally used in single-family housing. It describes the engineering of an efficient, multifaceted, and fully integrated water management system for a domestic environment of $800 \mathrm{sq}$. ft., entirely powered by solar energy. The four innovations whose details are conveyed include the use of alternate materials for piping distribution and collection, the use of water in solar energy generation, the design of a building skin which capitalizes on water's capacity to store heat as well as the design of a ecological groundscape which re-uses and filters waste water and rain water.
\end{abstract}

Keywords: energy, plumbing, home design

\section{INTRODUCTION}

This paper communicates the results of an architectural research project which sought innovative design strategies for achieving energy and resource efficiencies in water management systems traditionally used in single-family housing. A building's plumbing infrastructure, such as its supply, distribution and waste collection is rarely addressed when developing initiatives for improving sustainable practices within the construction industry. And yet, it is precisely this network of pipes, valves and controls which plays a considerable role in the total energy and resource consumption of any building. With an eye to addressing this condition, the following describes the engineering of an efficient, multifaceted, and fully integrated water management system for a domestic environment of $800 \mathrm{sq}$. ft. The four innovations whose details are conveyed include the use of alternate materials for piping distribution and collection, the use of water in solar energy generation, the design of a building skin which capitalizes on water's capacity to store heat as well as the design of an ecological groundscape which re-uses and filters waste water and rain water.

This paper was written collaboratively by studio instructor and graduate architecture student at the College of Architecture of the Georgia Institute of Technology, highlighting a process which openly promoted the integration of both research and design methodologies within existing pedagogical structures typical of architecture studios. It details conditions which facilitated extensive collaborations between student and industry specialists, suppliers and associated engineers. And conducted under the auspices of the Solar Decathlon 2007 Competition, the studio held in the fall of 2006 involved the collaboration of sixteen architecture students and an equal number of engineering and building technology students operating as consultants. The mandate to design, build and transport to Washington DC, a highly efficient single-family house entirely operated using solar power was the immediate context within which the plumbing design was developed. Managing the water consumption and waste redistribution of a one bedroom, one bath living environment using the least amount of energy was the express goal. In addition, the accommodation of a grey water system for recycling waste and rainwater became an important feature of the landscape design. The studio was productively constrained by the real life necessity to physically build and operate the results of one's invention. All decisions will see the light of day and be submitted to the rigorous testing of an international competition. This is the context within which the full merit of the work described here below should be evaluated. But a sub-section of the research and design work undertaken by an entire class of architect and engineer collaborators, it registers the gains achieved when asking questions pertinent to building performance, sustainable water management practices and the construction of solar powered homes. 
The results herein may be of interest to those involved in architectural education as well as those involved in the engineering of building systems. The adoption of sustainable practices and energy conservation, as they pertain to the operations of a building, has yet to become an essential component of architectural design as taught within most design studios. The perceived urgency to teach the language of form, site, program and circulation leaves little time for questions associated with architectural performance. And yet, with $40 \%$ of North America's energy consumption the result of operating a building's systems, the necessity to encourage dialogue between architect and engineer is imperative. This studio was the first initiative at Georgia Tech to posit questions of applied technology within the core of a collaborative studio and it is expected that a greater number of design studios will herein investigate the territory defined by architectural design, systems design and building performance. Architecture students collaborated extensively with undergraduate and graduate students from Mechanical, Civil, Electrical and Computing Engineering, and they constructively integrated the limitations of each within the process of design.

In addition, the outcome of such a project may be of keen interest to the building industry, who in this instance volunteered its services to help in the education of young architects. The project necessitated a large degree of collaboration between student and industry consultants as many working meetings were held with material and systems suppliers, installers and specialty contractors. Be it in the fields of heating, ventilating, cooling, lighting, electrical wiring, photovoltaic design or plumbing, students worked side by side with experts in each field and directly benefited from the practicum of those who have understand the in-situ operation of building systems. No longer are assumptions about details and performance acceptable in theory; they must accord with their measured values in practice.

And finally, the results of such a research and design project may be of interest to our future clients and home builders. The potential for ever more efficient building systems within residential construction is considerable given technological advances in non renewable energies during the past two decades. Housing projects such as Sutton, England's BedZED Development designed by Bill Dunster are showcases for the integration of innovative operating systems within contemporary architecture, particularly when architect and developer are intent on reducing to a minimum a project's daily consumption of non renewable energy (Sommerhoff, Emilie 2003). However, within the North American new housing market the evidence of such integration is scant. Reluctance still exists on the part of building contractors to install mechanical equipment which features such inventions when building single-family housing; not being the benefactors of their projected lower operating costs. Far more surprising, however, is the lack of advocacy on the part of architects and engineers to redress this situation. Surely, more awareness could be generated and information communicated to housing consumers on the long-term benefits of more energy efficient building systems and this paper is an attempt to facilitate this process.

\subsection{SAVING ENERGY AND RESOURCES BY WAY OF INNOVATIONS IN HOUSEHOLD PLUMBING}

What began as the need to engineer a simple plumbing diagram for a single-family residence expanded into an energy recycling, building integrated system of water management designed to capture the heat energy expended from a variety of sources. In so doing, it has made the plumbing system one of the most energy saving components of the contest house in question. The whole was accomplished by way of research using product data, manufacturer's recommendations, consultation with engineers and those with expert knowledge in plumbing design, and research into the operation of components in academic publications.

As mentioned previously, the four innovations in plumbing design and water management which resulted in energy efficiencies can be summarized as follows:

1. the use of alternate materials and distribution techniques for primary household needs

2. the adoption of water for solar energy collection

3. the use of water's capacity to store heat and the implication this has for the design of building skins

4. and the re-use of waste water and rain water in the development of more ecological groundscapes

(c) 2007 ARCC Spring Research Conference, Eugene, Oregon, April 16-18, 2007 


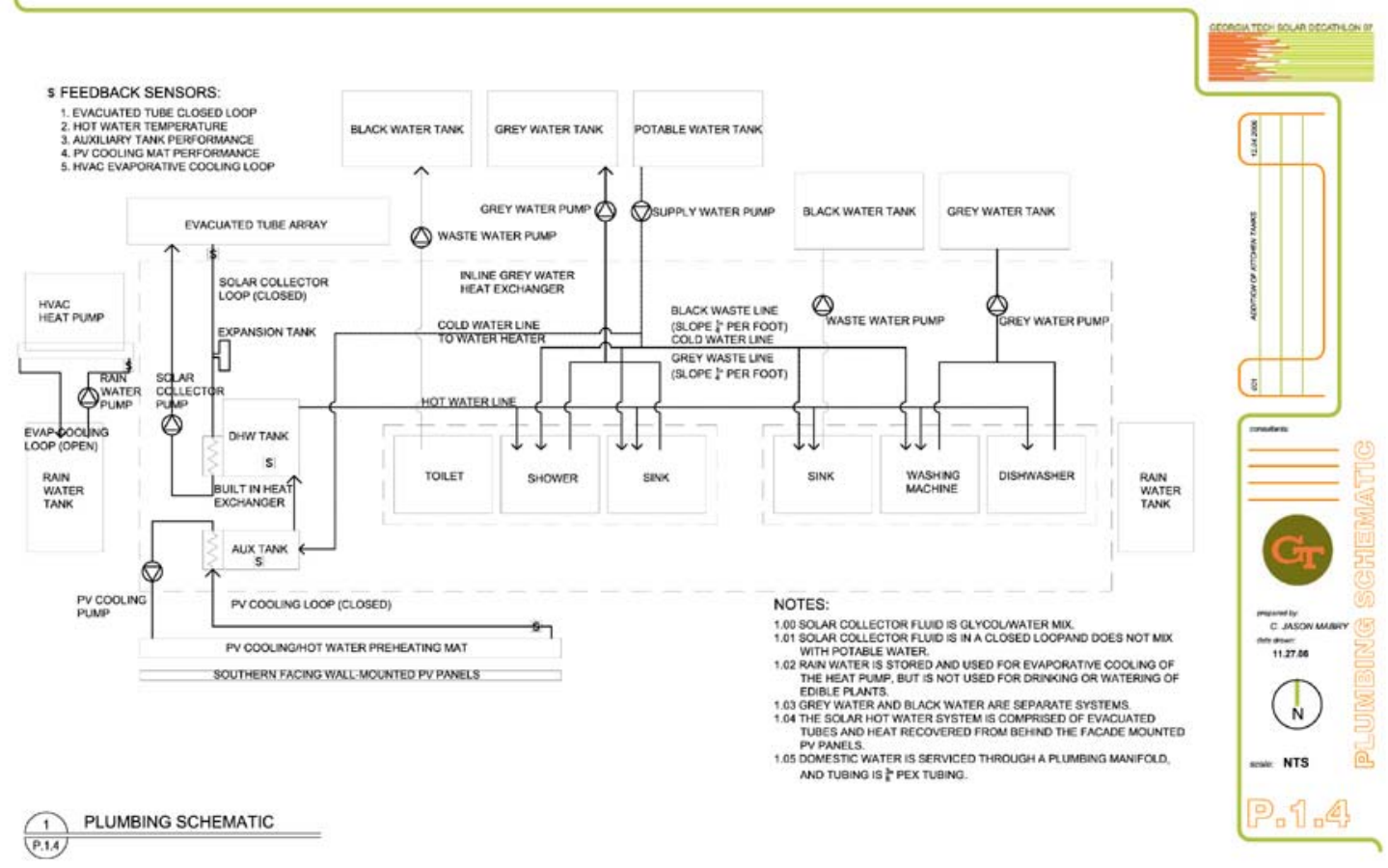

Figure 1: Plumbing schematic for the solar decathlon house. Source: Mabry 2006.

\subsection{Saving energy using alternate materials and distribution techniques for primary household needs}

The typical single-family home can greatly benefit from advances in the most ubiquitous of building products; pipes used in common plumbing applications. Research into innovative plumbing systems in the form of product searches yielded information on the newest technology to date: the home run system, or plumbing manifold. Two common companies manufacturing plumbing manifolds are Vanguard Industries, Inc. and REHAU, Inc., and while they have been around for several years, they are now coming into broader use.

The system functions by way of a central location from which all water is delivered to fixtures throughout the house. In this way water usage can be more easily monitored and controlled, leaks are easier to detect and fix, and it allows work being done on specific plumbing components to not hamper water delivery to the rest of the house (NAHB Research Center 2003). This plumbing manifold, essentially a breaker box for hot and cold water delivery, is both a method of saving energy in the plumbing system and a more efficient method of delivery. All water flows through the manifold and is then sent through individual lines to hot and cold water connections at each fixture.

The home run system saves energy by coupling the manifold with PEX piping as a delivery system. PEX is a flexible plastic made into tubes, and is especially well suited for plumbing due to its resistance to chemicals, heat, and creep (NAHB Research Center 2003). PEX runs as a single length of tubing between the manifold and the fixture, with no fittings required except at terminal points. Being made of cross-linked Polyethylene, it accommodates sharp bends, allows for quick and direct delivery of water with little pressure loss, and with resultant savings on pumping. Most critically, a smaller diameter PEX tube can be used than that of copper tubing, since the line runs are direct to each fixture without bends or material changes (Plastics Pipe Institute 2004). As such, instead of a $1 / 2$ " diameter supply tube (normally used with copper), a 3/8" diameter tube can be used in delivery to fixtures. This 1/8" has significant energy savings. The smaller diameter has approximately half the amount of water in it than the $1 / 2$ " tube (NAHB Research Center 2003). This means that there is less standing water in the tubes, and as a result less heated water will be left in the pipes to cool. Furthermore, the smaller diameter means that more water will be delivered in less time, since the velocity within the pipe will be higher (NAHB Research Center 2006).

In addition to being a more direct means of transferring water from the storage and hot water tank, PEX tubing has the added benefit of retaining more of the heat energy within the tube. Copper piping, the traditional method 
of delivery, is an excellent conductor, meaning it must either be insulated, or risk transferring the heat energy into the air of the house. PEX tubing acts as an insulator, and thus does not have the same problem, saving energy by retaining more of the heat within it. The use of PEX is becoming a major competitor to copper, due to cost and environmental issues, and has been in widespread use in Europe since the late 1970s (NAHB Research Center Nov 2006*).

For all of the above reasons it was decided to use this system in the construction of our Solar Decathlon House and in collaboration with Mckenney's Inc. and OneWorld Sustainable Energy Corporation the system will be optimized to efficiently deliver hot water while saving both water and the energy used to heat it. The plumbing plan takes advantage of a "power spine" concept wherein all of the piping distribution is contained within this spine and the location of the plumbing manifold has been identified as adjacent to the spine, located within the bathroom and in close proximity to the kitchen, allowing for fast and efficient delivery.

\section{Saving household energy with the use of solar hot water evacuated tubes}

Another means of reducing the consumption of energy in the operations of a typical household involves the introduction of solar hot water. The ability to use the sun's rays in order to heat a family's daily water usage is yet another means of reducing reliance on non-renewable energies. When researching solar hot water systems, most research indicated that evacuated tubes would be the most effective at capturing usable solar energy (National Renewable Energy Laboratory 2006). Flat plate collectors would be another option. Evacuated tubes operate by absorbing solar radiation into a tube from which air has been evacuated. The trapped radiation then heats a smaller tube through which a heat transfer fluid flows, absorbing the thermal energy. Since there is virtually no air inside the tubes, almost all energy captured is retained, instead of being lost through convection or conduction. The heat transfer fluid is then piped to a heat exchanger or solar hot water tank.

Typical evacuated tube design yields a high volume of heat production to unit size, more so than competing flat plate collectors (National Renewable Energy Laboratory 2006). Consultation and collaboration with engineering students during the initial design charrette supported the decision to use evacuated tubes. Furthermore, the design of the system usually limits the amount of pumping needed for the solar collection fluid, or eliminates it altogether by using thermosiphoning. Most typically, thermosiphoning could be defined as a passive system of heat exchange that eliminates the need for pumps within a vertical closed-loop circuit. A difference in temperature and thus liquid density allow for a thermosiphon heat exchange system to effectively capture and store solar energy in a tank without requiring a conventional pump, though the design is somewhat restrictive.

Due to constraints on the site whose dimensions were dictated by the Solar Decathlon competition, various manufactures and evacuated tube systems were studied to determine which would deliver the most energy in the least amount of space. This research commenced with manufacturer's details to determine spatial dimensions and restrictions, and concluded with independent research conducted by collaborating PhD engineering students engaged in in-depth analyses of the competition house systems. Additionally, since the roof, usually the ideal location for such a system, is in our design completely covered in solar panels, it was necessary to move the system to a lower but equally effective location. Product research of various available manufacturers located a system that allowed horizontal operation instead of the usual angled vertical configuration. This coincided with a desire to integrate the system into the architecture and landscaping, showcasing the energy producing technology on the outside of the house, and produced a more cohesive architecture/systems and engineering design and approach to the project.

To save on losses due to pumping distance, the evacuated tubes were located as close to the water heater as possible. Several thermal storage systems were examined, both by speaking with industry professionals and studying as-built drawings showing how other groups had constructed evacuated tube thermal energy storage systems in the past, mainly from past Solar Decathlon competitions. The decision was made to keep the system as simple as possible while still creating and storing as much energy as possible. Using a large solar storage tank was ruled out since there was no room within the structure to house it, and because it would allow the dissipation of heat into the air had it been external to the building envelope. Additionally, the auxiliary tank would require extra pumping to deliver the energy to another tank. Therefore, a direct evacuated tube to hot water tank system was designed, at first as a conceptual design, then further refined with feedback from engineering students working on the project, and finally refined and approved by consultants from the engineering firm Mckenney's Inc. Utilizing a hot water tank with a built in heat exchanger will save energy losses due to pumping. Thus, the glycol/water loop delivers energy directly from the evacuated tube to the hot water tank by means of the integrated heat exchanger. With the exchange occurring within the tank, no heat is lost to the environment in the process, further saving on energy.

(c) 2007 ARCC Spring Research Conference, Eugene, Oregon, April 16-18, 2007 


\section{Saving Household Energy by way of Heat Storage in the Design of an Exterior Cavity Wall}

The most elaborate component of the house's plumbing system will be located within the south facing structurally insulated panel (SIP) wall assembly. Comprising simultaneously building skin, cooling system, heating system, and systems/architecture integration, a so-named PV cooling loop will be introduced into the design of the house's front elevation. This particular section of the façade is comprised of solar collectors traditionally situated on the roof. They are offset from the SIP wall by a cavity in which the cooling loop will be located. In this instance a plumbing loop has been devised to act as both water heating element and PV cooling component. The water heating portion of the system was deemed necessary by engineering calculations due to site constraints in the sizing and location of the evacuated tubes, the primary water heating element. This heating system was required to be placed much farther than optimal from the water heater, and since the overall house design and other stringent criteria forced the evacuated tube system to be smaller than would be ideal, a secondary solar heating method was sought, which led directly to the water in the wall heating system. This was devised in collaboration with a fellow studio student working on the wall assembly and PV panel integration.

Due to the inclusion of solar panels on the wall, where less airflow would be available, it was determined that a method of cooling would be required to maintain their performance. It was also realized that the heat buildup behind the panel would be usable waste heat if it could be stored. By capturing this heat, it would be useful elsewhere within the house. Heating water was the obvious choice for the captured thermal energy. Coupling any retrievable heat from behind the panels with the output of the evacuated tubes seemed sufficient for all water heating needs. The question then revolved around how to best retrieve the heat from behind the panels.

A separate study, conducted by another studio participant, investigated the efficacy of wall-mounted PV panels (Krauter, Stefan 2001). This study examined methods of extracting heat from behind PV panels to allow them to operate most efficiently. Of the four viable methods, the most effective was using liquid to remove excess heat (Krauter, Stefan 2001). The research results identified by the student confirmed the studio led research assumptions and closely aligned with efforts of placing piping behind the PV panels on the SIP wall.

Research into specific cooling methods conducted by a fellow studio participant studying PV facades coincided with specific heating methods and piping choices examined from a plumbing standpoint, allowing for the system to serve multiple purposes. The study on extracting heat from behind the panels did not indicate which liquid would be most effective at extracting heat, but research into the evacuated tube system indicated that a glycol/water mixture would best transfer heat and be useful in the prevention of freezing within the system (National Renewable Energy Laboratory 1996). Advice from field experts at Mckenney's, Inc. also confirmed this conclusion. Thus, the same fluid used to transfer heat in the evacuated tubes will be used to extract heat from the PV panels and supplement the primary water heating system.

The final question remaining in the water system was which type of piping should be used. Due to the compact nature of the system, spatial restraints between the panel and the wall, investigation into a very slim heat extraction system was undertaken to determine whether or not there was a system that would fit. After searching for premade systems, of which none specific to this type of application were found, the decision was made to custom design and construct one. Such systems were initially developed in the 1970s for water heating, typically used in heated pool applications, but none are currently in production. Copper piping and PEX piping were the two products of investigation for carrying the fluid. After much research into the best methods of circulating liquid for heat extraction, primarily in the form of conversations with field experts, in addition to product data research, it was found that straight lines running vertically would not be as efficient at removing heat since they would not cover enough area. Copper piping, aside from being increasingly expensive, is not as maneuverable as PEX tubing, and given the space constraints, and the understanding that copper would be much more difficult to work with, PEX was chosen as the piping method of choice. OneWorld Sustainable Energy Corporation in Atlanta, Georgia has acted as a consultant in this process and their research into manufacturer's specifications and similar heating systems made with rubber mats and PEX tubing indicated that such a system would work well for the project's purposes. PEX can bend back and forth, snaking up the SIP wall and thereby extracting extra heat that would not be possible in a straight pipe configuration. This extra heat will allow for further energy savings by limiting the amount of time the auxiliary heating element would need to operate to deliver hot water.

In the end, it was determined that cooling the PV panels while heating water using the glycol/water mix and a heat exchanger would be very effective at saving energy used to heat hot water within the house, in addition to providing increased solar energy output from the PV panels by allowing them to operate more efficiently. Both the hot water system and the power production system will now operate better together than either would have alone. In addition, this coupling of plumbing components has resulted in a unified system integrating architecture and infrastructure.

(c) 2007 ARCC Spring Research Conference, Eugene, Oregon, April 16-18, 2007 


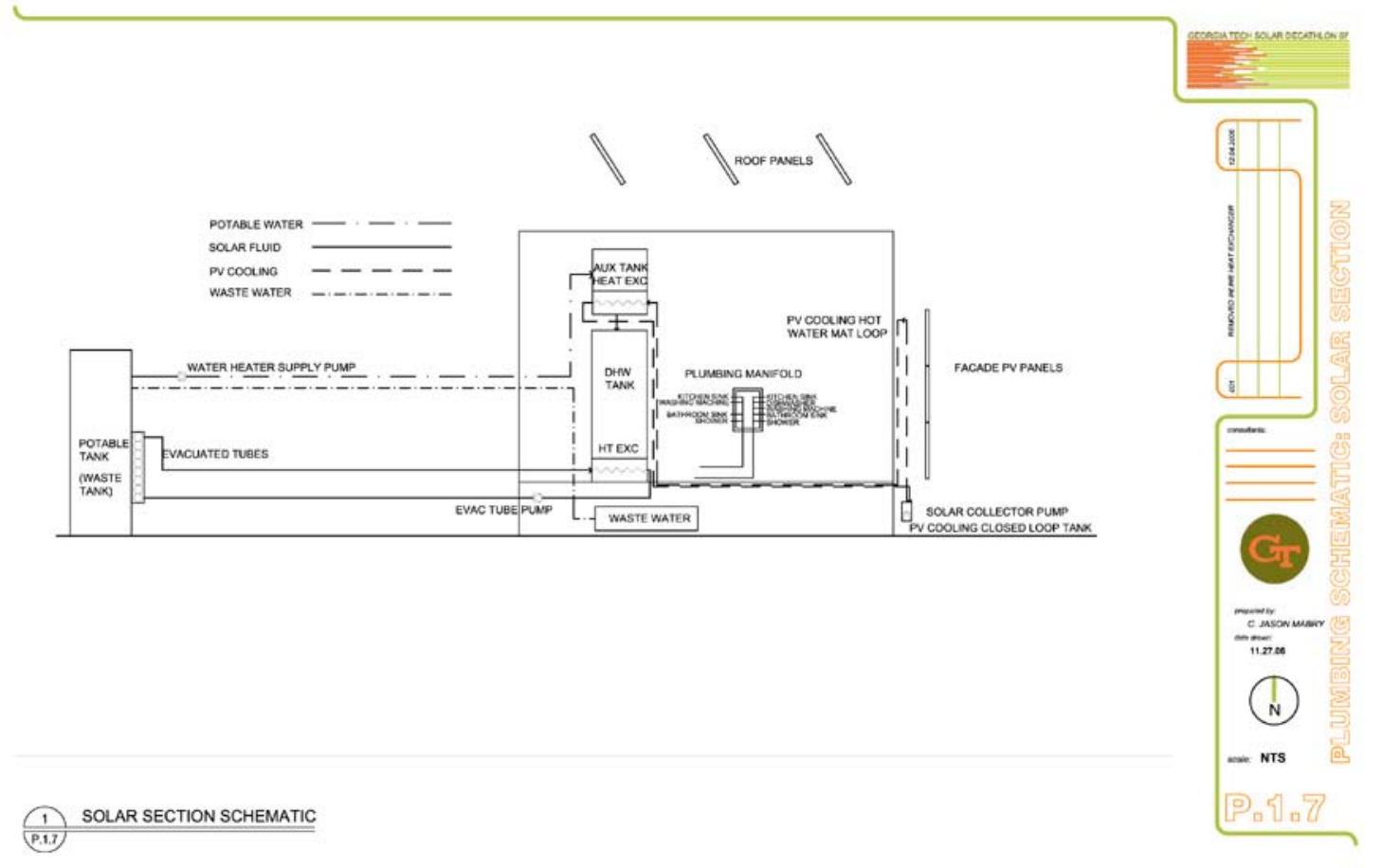

Figure 2: Solar schematic section for the solar decathlon house. Source: Mabry 2006.

\section{Saving energy with water in the landscape}

In the process of designing the house, whose plumbing systems both within and without have been described here above, the decision was made to render the larger site within which it was situated into a working landscape; a natural machine in support of the house. By using the ground which surrounds the house for the cleaning and storing of water, a net supply of energy will be saved in the house's operations. Water used both in the house and collected on site will not be immediately disposed of and sent afar to be processed and treated at a water purification plant. The design intent ensures that as much as possible of the water that is found on the site remains on the site. And to this end, some of the house's internal water will be recycled on site as will captured rain water. This will save on potable water usage and sustain the larger landscape while reducing both the house's and the municipality's operating costs, reducing piping required and energy required to treat the water.

The house has been designed to have both a grey water and black water system. They are kept separate, allowing for the onsite treatment of the grey water, and the eventual offsite processing of the black water. Grey water originates in plumbing sites such as the bathroom sink, shower, dishwasher, and washing machine, and when properly treated can be recycled for use in toilet flushing, clothes washing, and irrigation. Storm water collected from outdoor decks and the building roof is also considered grey water and it too can be used for the same purposes. Efforts are ongoing with engineers to attempt to extract thermal energy from grey water prior to storage or discharge into the landscape. This can be achieved by using an inline heat exchanger or by passing the heated grey water in immediate proximity of incoming supply water to transfer the heat between the lines prior to exiting the house envelope. Current research is determining feasibility of such a system and the technical difficulties in extracting the energy.

The system is designed to efficiently treat grey water in a limited footprint, due to competition constraints. Furthermore, a complex system of tanks is required as there is no municipal hookup and all water must be stored on site. The potable water supply tank is used in the landscape to supply water to edible plants, due to competition constraints disallowing edible plants to be treated with grey water. The grey water tank supplies water to a reed bed filtration system developed in collaboration with two fellow studio members focusing on the landscape design and implementation alongside a civil engineering student also working on grey water filtration. The filtration system pumps water to an elevated tank, and from there gravity moves the water from tank to tank. 
A complex series of plants and organisms pull nutrients from the water for their own sustenance and then pass cleaner water to the next tank, ultimately releasing it into the landscape. There is also a living wall, essentially plants stacked vertically in containers that will be irrigated by grey water. Rainwater is being collected in two tanks, one on each end of the house. One of these tanks will store rainwater that will be circulated through an evaporative cooling loop which will cool the heat pump used for the houses heating and cooling needs. Excess water will be used to irrigate the landscape. The other tank will also be used to irrigate the landscape, but will be preceded by an overflow tank that acts as a landscape element, storing water from heavy rains that can potentially be used to passively cool the house.

In addition to saving energy, the integration of the landscape into the house system, often an overlooked component, especially when considering energy saving measures, can be just as important as the mechanical, electrical, and plumbing systems. Moreover, the landscape machine beautifies the environment while cleaning it. By utilizing a complex system of several types of natural environments, gravity, and storage, water can be recycled with virtually no energy used in the process.

\section{CONCLUSION}

In conclusion, design research was conducted within the modified structure of an architectural studio. It served as the main platform from which investigations could be made into energy savings measures associated with plumbing systems used in residential construction. To accomplish the like, the input of expert engineering consultants was essential as was that of engineering students. Whether in the form of design reviews or working conversations, collaboration with such partners in the building industry proved crucial to the decision making process. Only in this manner could conclusions be drawn which encourage the use of innovative materials in the housing sector, which promote the use of solar technologies for conditioning our daily consumption of household water, which integrate the distribution of water in the construction of residential building skins and which consider the effects of water management across the entire site of a single-family home.

\section{ACKNOWLEDGEMENTS}

The authors would like to express thanks to all consultants who worked on the project: Greg Jeffers and Mckenney's, Inc. Engineers, OneWorld Sustainable Energy Corporation, Professor Ruchi Choudhary, and students Toni Cliett [Architecture], Amanda Cook [Architecture], Erin Gibbons [Civil Engineering], Alex Jackson [Civil Engineering], and Joe Jamgochian [Architecture].

\section{REFERENCES}

Krauter, S., Salhi, M., Schroer, S., Hanitsch, R. 2001. New Façade System Consisting of Combined

Photovoltaic and Solar Thermal Generators with Building Insulation.

NAHB Research Center. 2006. Home Run Plumbing Systems.

NAHB Research Center. 2006*. Design Guide: Residential PEX Water Supply Plumbing Systems.

NAHB Research Center. 2003. PATH Technology Inventory Review.

National Renewable Energy Laboratory. 1996. Residential Solar Heating Collectors.

National Renewable Energy Laboratory. 1996. Solar Water Heating.

Plastic Pipe and Fittings Association. PEX Offers Environmentally Sound Solutions.

Plastics Pipe Institute. 2004. PEX Pipes for Plumbing.

Sommerhoff, Emilie. 2003. Carbon Neutral Neighborhood. Architecture Vol. 92 Issue 4. 